Article

\title{
Energy Sustainability: A Pragmatic Approach and Illustrations
}

\author{
Marc A. Rosen
}

Faculty of Engineering and Applied Science, University of Ontario Institute of Technology, 2000

Simcoe Street North, Oshawa, Ontario, L1H 7K4, Canada; E-Mail: marc.rosen@uoit.ca; Tel.: +1-905-721-8668; Fax: +1-905-721-3370

Received: 9 March 2009 / Accepted: 27 March 2009 / Published: 30 March 2009

\begin{abstract}
Many factors to be appropriately addressed in moving towards energy sustainability are examined. These include harnessing sustainable energy sources, utilizing sustainable energy carriers, increasing efficiency, reducing environmental impact and improving socioeconomic acceptability. The latter factor includes community involvement and social acceptability, economic affordability and equity, lifestyles, land use and aesthetics. Numerous illustrations demonstrate measures consistent with the approach put forward, and options for energy sustainability and the broader objective of sustainability. Energy sustainability is of great importance to overall sustainability given the pervasiveness of energy use, its importance in economic development and living standards, and its impact on the environment.
\end{abstract}

Keywords: Energy; Sustainability; Renewable energy; Efficiency; Environment; Economics; Exergy; Life cycle analysis.

\section{Introduction}

Energy sustainability is becoming a global necessity, given the pervasive use energy resources globally, the impacts on the environment of energy processes and their reach beyond local to regional and global domains, and the increasing globalization of the world's economy. Energy is directly linked to the broader concept of sustainability and affects most of civilization. That is particularly evident since energy resources drive much if not most of the world's economic activity, in virtually all economic sectors, e.g., industry, transportation, residential, commercial. Also, energy resources, whether carbon-based or renewable, are obtained from the environment, and wastes from energy processes (production, transport, storage, utilization) are typically released to the environment. Finally, the services provided by energy allow for good living standards, and often support social stability as 
well as cultural and social development. Given the intimate ties between energy and the key components of sustainable development, the attainment of energy sustainability is being increasingly recognized as a critical aspect of achieving sustainable development.

Energy sustainability is taken here not just to be concerned with sustainable energy sources, but rather to be much more comprehensive. That is, energy sustainability is taken to involve the sustainable use of energy in the overall energy system. This system includes processes and technologies for the harvesting of energy sources, their conversion to useful energy forms, energy transport and storage, and the utilization of energy to provide energy services such as operating communications systems, lighting buildings and warming people in winter. Thus, energy sustainability goes beyond the search for sustainable energy sources, and implies sustainable energy systems, i.e., systems that use sustainable energy resources, and that process, store, transport and utilize those resources sustainably.

Sustainable development is increasingly becoming a goal to which countries aspire. Overall sustainability has been defined in many ways, and is often considered to have three distinct components: environmental, economic and social. These three factors when considered separately usually pull society in different directions (e.g., economic sustainability may be achieved at the expense of environmental and social sustainability). Overall sustainable development in general requires the simultaneous achievement of environmental, economic and social sustainability. Achieving this balance is challenging, and energy factors into each component.

The objective of this article is to examine the key factors to be addressed in achieving energy sustainability in a global context and to integrate them into a pragmatic approach to energy sustainability. A technical perspective is often taken in part because of the importance of technical factors in energy sustainability and also to be practical. This article extends research previously reported on energy sustainability [1], by formulating a pragmatic approach and demonstrating the concepts with a range of illustrations, intended to provide examples of practical sustainable energy options.

The emphasis in this article of technical aspects of energy sustainability is in part influenced by the author's experiences as a professional engineer, an engineering educator and administrator and the head of engineering societies. This approach is also taken to be pragmatic, which is often at the centre of engineering activities, and because it focuses on the technical necessities to achieve energy sustainability, and less on the roles of economics, politics and other non-technical factors. Consequently, the present article is not the approach that would likely be taken by economists, business and industry leaders, politicians or sociologists, who have different foci and different paradigms through which they view energy sustainability. The approach based on technical factors is taken to assist efforts to move society towards energy sustainability, but is not necessarily comprehensive.

The pragmatic approach taken here is considered critical by the author for addressing the fundamental issues and challenges relating to energy sustainability, for several reasons. First, although the economics and politics of energy vary temporally and spatially and have geopolitical ramifications, the underlying fundamental issues involved in achieving energy sustainability are in many ways mainly technical and are in several respects separate from other factors. Second, energy prices are somewhat artificial as they can be greatly affected by political forces like taxes, rebates, incentives, 
penalties and limits; costs and prices are tools which can be used to achieve desired aims (e.g., energy sustainability). Third, a sound technical basis is essential for avoiding confusion, which is often significant. For instance, the terms energy conservation makes no sense technically since the first law of thermodynamics stipulates that energy is conserved; the intended meaning usually is the conservation of high-quality and useful energy commodities like oil, demonstrating the need for a sound technical basis for rationally addressing energy sustainability. Finally, the general concept of sustainability often lacks in rigour [2], and many feel a discipline of sustainability science and engineering is needed. For instance, the Ontario Power Authority in Canada included sustainability as a key factor in its plan for the energy future of Ontario, Canada [3], but found a clear methodology for energy sustainability to be lacking. The approach taken here in addressing energy sustainability is intended to focus on the essential aspects of and needs for energy sustainability.

\section{Background}

To appreciate the concepts underpinning energy sustainability, it is informative to consider the concept and definitions related to energy sustainability and sustainable development.

\subsection{Energy}

Energy is used in almost all facets of living and in all countries, and makes possible the existence of ecosystems, human civilizations and life itself. Different regions and societies adapt to their environments and determine their own energy resources and energy uses. The standards of life achieved in countries are often a function of energy-related factors.

Energy can exist in many forms, and can be converted from one form to another with energyconversion technologies. We use energy carriers (often simply referred to as energy), produced from energy sources, in all aspects of living. It is important to distinguish between these terms [4]:

- Energy forms: Energy comes in a variety of forms, including fossil fuels, fossil fuel-based products (e.g., gasoline, diesel fuel), uranium, electricity, work (such as the mechanical energy in a rotating engine shaft), heat, heated substances (e.g., steam, hot air), light and other electromagnetic radiation.

- Energy sources: Energy resources (sometimes called primary energy forms) are found in the natural environment. Some are available in finite quantities (e.g., fossil fuels, fossil fuelcontaining substances, peat and uranium). Some energy resources are renewable (or relatively renewable), including solar energy, falling water, wind, tides, geothermal heat and biomass fuels (when the growth rate is not below the rate of use). Energy resources are often processed from their raw forms prior to use.

- Energy carriers: Energy carriers (or currencies) are the energy forms that we use, and include some energy resources (e.g., fossil fuels) and processed energy forms (e.g., gasoline, electricity, work and heat). Processed energy forms are not found in the environment.

Some points on energy carriers are worth noting. First, they are closely related to endeavours of people and societies, representing the direct energy forms used to deliver needed or desired energy services. Thus, energy carriers influence living standards and are related to technological development. 
Also, the difference between energy carriers and sources is important. Energy carriers can exist in a variety of forms and can be converted from one form to another, while energy sources are the original resource from which an energy carrier is produced. Confusion sometimes results between energy sources and carriers because some energy sources are also energy carriers. Hydrogen for example is not an energy source, but rather an energy carrier that can be produced from a wide range of resources using various energy-conversion processes (e.g., water electrolysis, reforming of natural gas and coal gasification). Nevertheless, hydrogen is often erroneously referred to as an energy source, especially in discussions of its potential future role as a chemical energy carrier to replace fossil fuels.

\subsection{Sustainability}

Sustainable development was defined by the 1987 Brundtland Report of the World Commission on Environment and Development [5] as "development that meets the needs of the present without compromising the ability of future generations to meet their own needs." This definition implies that actions of present societies should not threaten cultures or living standards for societies. Other definitions and descriptions have been presented. The degree to which sustainable development can be achieved by countries varies, since countries differ according to such characteristics as size, wealth, living standards, culture, and political and administrative systems. Wealth and advanced technology may make it easier for industrialized countries to strive for sustainable development, but this is not always the case. The basic motivations and desires of societies, countries, cultures and people to advance appear to be inherent, and these aspirations often require increasing energy use and often yield correspondingly increasing emissions.

\subsection{Energy Sustainability}

In some ways, the concept of energy sustainability is simply the application of the general definitions of sustainability to energy. In other ways, energy sustainability is more complex and involved. Energy sustainability involves the provision of energy services in a sustainable manner, which in turn necessitates that energy services be provided for all people in ways that, now and in the future, are sufficient to provide basic necessities, affordable, not detrimental to the environment, and acceptable to communities and people. Universal agreement on a definition of energy sustainability has not yet been achieved, but various definitions and descriptions have been presented [2,6-14]. Linkages between energy sustainability and factors such as efficiency and economic growth have been investigated [15].

The connection between energy, the environment and sustainable development is worth highlighting. Energy supply and use are related to climate change as well as such environmental concerns as air pollution, ozone depletion, forest destruction, and emissions of radioactive substances. These issues must be addressed if society is to develop while maintaining a healthy and clean environment, especially since the future will be negatively impacted if people and societies continue to degrade the environment. A society seeking sustainable development ideally must utilize only energy resources which cause no environmental impact (e.g., which release no emissions or only harmless emissions to the environment). However, since all energy resources lead to some environmental impact, improved efficiency and environmental stewardship can help overcome many of the concerns 
regarding the limitations imposed on sustainable development by environmental emissions and their negative impacts.

\section{Approach to Energy Sustainability}

There are several distinct components to the manner in which energy resources can be used sustainably in society, each of which is a requirement for energy sustainability. In the following sections, each of these aspects of energy sustainability is described and examined.

\subsection{Harness Sustainable Energy Sources}

The requirements for energy services need to be satisfied, and sustainable energy sources need to be utilized for that objective. This will be a particularly challenging task as the use of energy resources increases with increasing populations and living standards, especially as developing countries become more industrialized and affluent. Many non-renewable and renewable energy sources are listed in Tables 1 and 2, respectively. Non-renewable energy sources include energy resources which are available in limited quantities. Fossil fuels are non-renewable, as are other sources like uranium, although nuclear fuel lifetimes ultimately depend on the development of advanced nuclear technologies like breeder reactors [16-19]. Renewable energy includes solar radiation incident on the earth, and energy forms that result from that radiation, as well as energy from such other natural forces as gravitation and the rotation of the earth. Solar radiation, which is incident on the Earth at 20,000 times the global energy-use rate, can be collected as heat or concentrated to high-temperature heat or converted directly to electricity in photovoltaic devices. Several other renewable energy types stem from solar radiation. Hydraulic energy, which includes falling and running water, ranges in size from large complexes like at Niagara Falls to much smaller systems like microhydro. Ocean thermal energy is based on the temperature difference between surface and deep waters, which can be exploited to generate electricity. There are two distinct types of geothermal energy: hot, which utilizes the internal heat of the Earth, and ambient (i.e., natural ground temperature), which can be used by ground-source energy systems like heat pumps. Tidal energy exploits the motion with tides caused by gravitational forces of the sun and moon and the rotation of the earth, while wave energy is based on the motion of waves. Biomass energy includes wood (e.g., fast-growing trees or forestry wastes), plants and other organic matter, which can be combusted or converted to other fuels. Biomass energy is only a renewable resource when the rate at which it is used does not exceed the rate at which it is replenished. Wastes (material and heat) can be considered either renewable or non-renewable energy, and can be used to produce heat or to generate electricity via waste-to-energy incineration.

Non-fossil fuel energy options reduce or eliminate greenhouse gas emissions and thus often facilitate sustainable energy solutions, although some like biomass can lead to net emissions if not managed carefully. Although non-renewable, nuclear energy avoids greenhouse gas emissions. Nonfossil fuel energy options are diverse in their characteristics and types, ranging from renewables to nuclear energy. 
Table 1. Non-renewable energy sources.

\begin{tabular}{l}
\hline Fossil fuels \\
Coal \\
Oil \\
Natural gas \\
Tar sands \\
Oil shales \\
Peat \\
Non-fossil fuels \\
Biomass (when not replenished) \\
Uranium \\
Fusion material (e.g., deuterium) \\
Wastes
\end{tabular}

Table 2. Renewable energy sources.

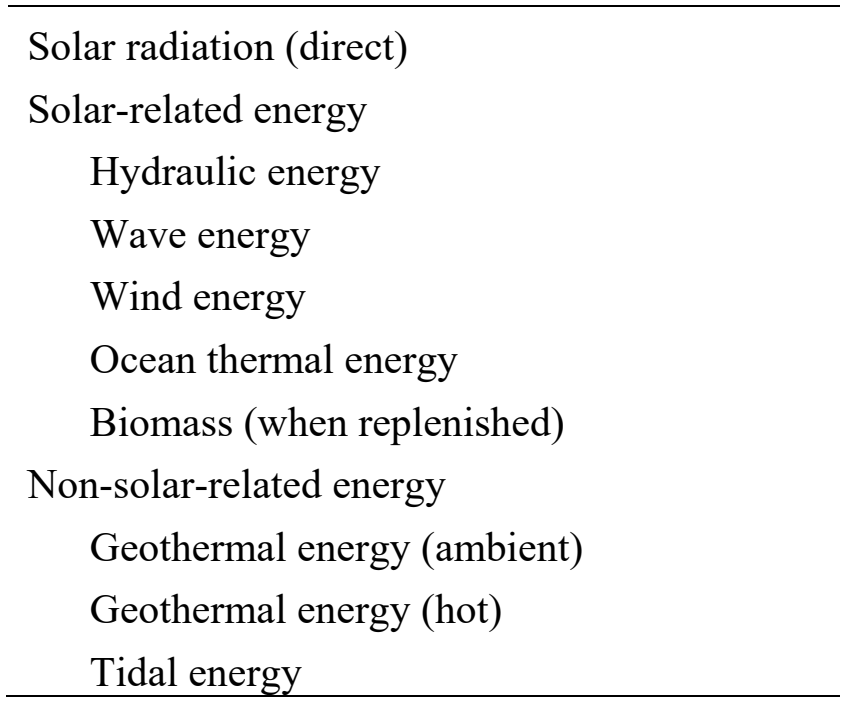

\subsection{Utilize Sustainable Energy Carriers}

Utilizing sustainable energy carriers usually implies the conversion of sustainable energy sources into appropriate energy carriers. The range of energy carriers is diverse (see Tables 3 and 4). Material energy carriers include secondary chemical fuels, ranging from such conventional ones as oil products (e.g., gasoline, diesel fuel, naphtha), coal products (e.g., coke) and synthetic gaseous fuels (e.g., coal gasification products), to non-conventional chemical fuels like hydrogen, methanol and ammonia. Thermal energy can be either heat (or a heated medium such as hot air, steam and exhaust gases) or cold (or a cooled medium such as cold brine and ice), and can be transported via district energy systems. For example, buildings in some cities are connected by pipes through which hot water or steam flows to provide space and water heating, while district cooling uses a piping network to provide cooling. Energy carriers in general are an important consideration in energy sustainability because conventional and non-fossil fuel energy options are not sufficient for avoiding environmental issues 
such as climate change, in that they are not necessarily readily utilizable in their natural forms. Conversion systems are often needed to render non-fossil energy more conveniently utilizable.

Table 3. Material energy carriers.

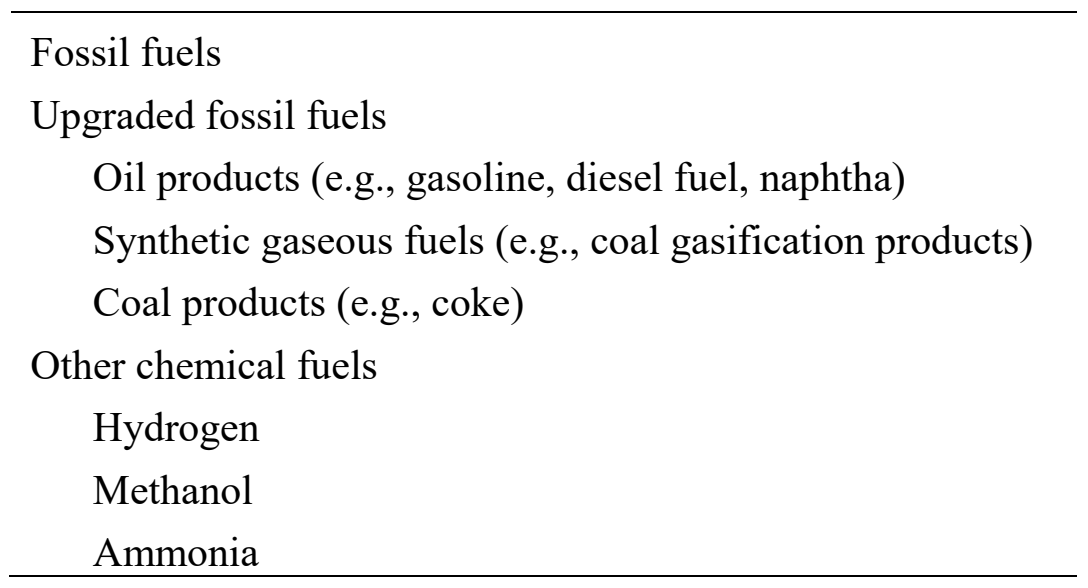

Table 4. Non-material energy carriers.

\begin{tabular}{l} 
Work \\
Electrical energy \\
Thermal energy \\
Heat (or a heated medium) \\
Cold (or a cooled medium) \\
\hline
\end{tabular}

Hydrogen energy systems are considered particularly important as they facilitate the use of nonfossil fuels by allowing them to be converted to two main classes of energy carriers: hydrogen and electricity. Together, these two energy carriers allow most chemical and non-chemical energy needs to be satisfied in a sustainable manner, provided the carriers are produced from sustainable energy resources. Hydrogen demand as an energy carrier is expected to rise dramatically over the next few decades, as a "hydrogen economy" emerges [12,13,20-22]. In such an energy economy, hydrogen will likely be used in power generation, transportation and oil sands processing. Numerous approaches to a hydrogen economy have been reported by nations, e.g., Canada [23], the United States [24] and Iceland [25]. A key part of a hydrogen economy is hydrogen production. Hydrogen can be generated from fossil fuels, as well as processes not potentially fossil fuel-based, including water electrolysis using electricity and thermochemical water decomposition using thermal and/or electrical energy $[22,26]$. The latter two processes split water into hydrogen and oxygen. Pathways to hydrogen energy have been investigated, focusing on renewable energy options [27] and the potential contributions of nuclear energy [28,29].

\subsection{Increase Efficiency}

High efficiency allows the greatest benefits to be attained from energy options and reduces environmental intrusions, and thus aids sustainability efforts. Efficiency improvements also include 
energy conservation, fuel substitution, improved energy management, better matching of energy carriers and demands and more efficient utilization of energy quality. Of course, the effectiveness of energy efficiency measures must be considered, and many have pointed out that, contrary to expectations, more efficient use of energy occasionally through "rebound" effects leads to little or no decrease in the consumption of energy resources, and sometimes to increased consumption [30,31]. Such rebound effects have led some to question the degree to which efficiency can improve environmental quality and facilitate sustainability [32]. In addressing efficiency of energy use, it is worth noting that energy is characterized by the laws of thermodynamics, with the first law embodying the principle of energy conservation and the second law relating to energy quality and often including entropy and exergy concepts.

Many efficiency improvements are best considered with exergy [33], which stems from the second law of thermodynamics. Exergy is similar to energy in some aspects, but different in others, e.g., the exergy of an energy form or a substance is a measure of its usefulness or quality. Exergy is defined as the maximum work which can be produced by a flow of matter or energy as it comes to equilibrium with a reference environment, and is a measure of the potential of a flow to cause change as a consequence of being in disequilibrium with the reference environment. Models for the reference environment exist, like the one in Figure 1 that simulates the natural environment. Exergy analysis often reveals insights not identified with the more conventional energy analysis [33-35]. Exergy analysis identifies meaningful efficiencies and thermodynamic losses in a process and is consequently beneficial in the analysis, design and improvement of energy systems and processes. Exergy analysis can reveal whether or not, and by how much, it is possible to design more efficient systems by reducing inefficiencies. Exergy is not conserved, but instead is consumed or destroyed due to the irreversibilities in any process. Exergy losses occur through both waste exergy emissions and internal exergy destructions. The exergy method is particularly useful for attaining more efficient energy-resource, and therefore greatly assists sustainability efforts. Exergy can also contribute to energy sustainability in other ways, because it can be used in conjunction with economics [11,36,37] and environment and ecology [10,33,38]. In the latter exergy provides a potential indicator of environmental impact. Exergy analysis has found applications in such areas as electricity generation, cogeneration, chemical processing, energy storage and hydrogen technologies [36,39-45].

\subsection{Reduce Environmental Impact}

Numerous environmental impacts associated with energy processes are of concern and must be addressed in efforts to attain energy sustainability, including:

- acidification (the impact on soil and water of acidic emissions),

- ozone depletion (i.e., destruction of the atmospheric ozone layer and subsequent increases in ultraviolet reaching the earth's surface),

- abiotic resource depletion (due to the extraction of non-renewable raw materials),

- radiological effects (e.g., radiogenic cancer mortality or morbidity due to internal or external radiation exposure),

- ecotoxicity (health problems from exposure to toxic substances), and 
- global warming (attributable mainly to greenhouse gas emissions and considered to be a key driver of climate change).

Figure 1. Illustrative representation of a reference-environment model based on the natural environment. All parts are at the reference-environment temperature and pressure. Saturated air is typically taken on a mass basis to be composed of nitrogen $(75.6 \%)$, oxygen $(20.4 \%)$, water vapour $(3.0 \%)$, argon $(0.9 \%)$, carbon dioxide $(0.03 \%)$ and hydrogen $(0.01 \%)$. The condensed phases for the lithosphere often include limestone and gypsum.

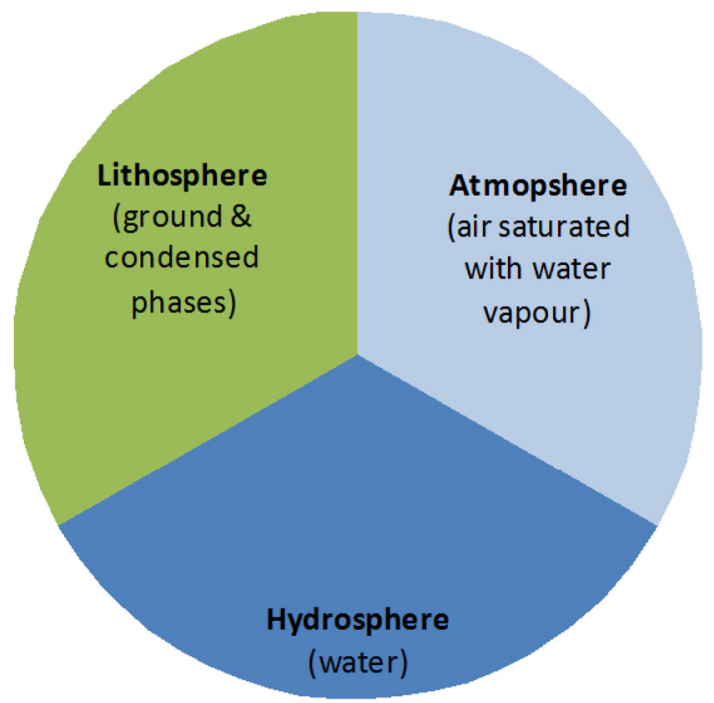

The latter concern is viewed by many as the most urgent environmental impact facing humanity. Mitigating climate change requires non-fossil fuel energy options, in that they avoid or greatly reduce emissions of greenhouse gases (gases that absorb radiation in the 8 to 20 micrometer region), particularly carbon dioxide. Non-fossil fuel energy sources can provide a foundation for the supply of sustainable energy services, which are a prerequisite for energy sustainability and sustainable development [35]. To better understand global warming, it is helpful to note that most of the energy entering the earth's atmosphere eventually exits back to space (see Figure 2) since, in terms of an earth-sun-space energy balance, energy input - energy output = energy accumulation. The energy input is the solar radiation entering the atmosphere, the energy output is the radiation exiting the atmosphere to space, and the energy accumulation is the increase in energy of the earth system (including its atmosphere). The average temperature of the earth is relatively constant when there is no energy accumulation, i.e., global warming is not present, and the planet's energy output and input are equal. This earth-sun energy balance is disrupted by global warming since increased atmospheric greenhouse-gas concentrations cause the energy output from the earth and its atmosphere to decrease while energy input remains constant. Thus, energy is accumulated, leading to an increase in the mean global temperature. If atmospheric concentrations of greenhouse gases stabilize at new levels, the energy balance is re-established but at some higher average planetary temperature. 
Figure 2. Earth-sun-space energy balance.

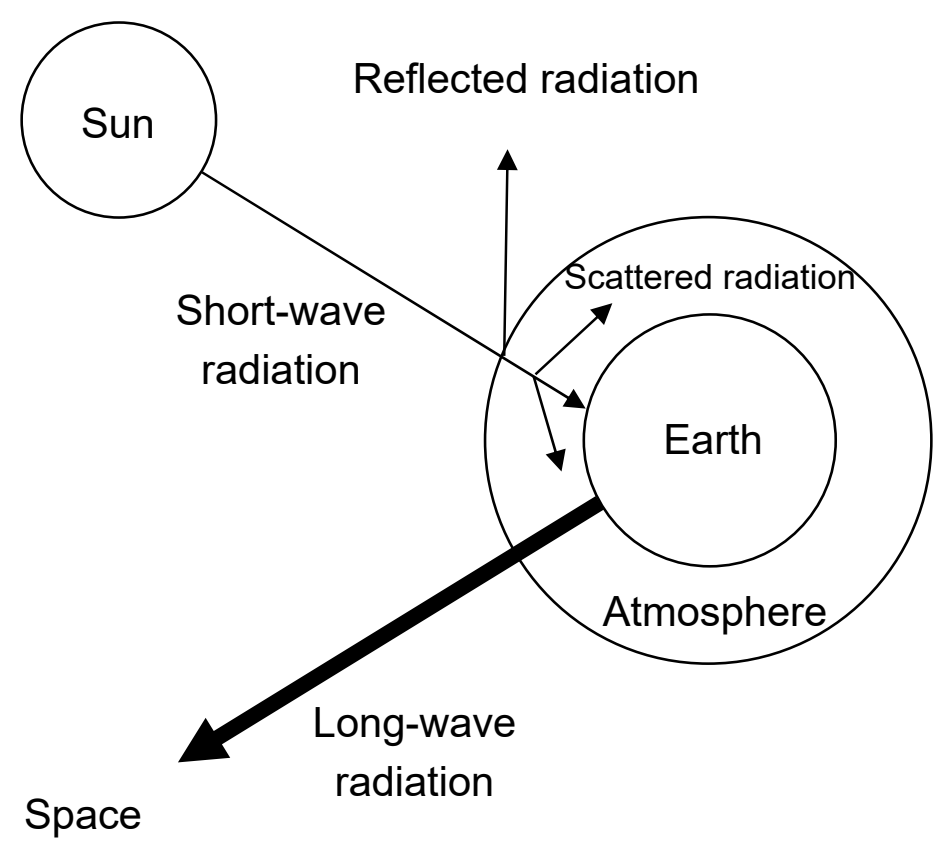

The source of the main greenhouse gas, carbon dioxide, is emissions during the combustion of fossil fuels, in furnaces, power plants, vehicles, manufacturing etc. A fossil fuel can be modelled as a hydrocarbon, and the link between global warming and fossil fuels can be observed by examining a qualitative chemical expression for combustion in oxygen (neglecting leftover reactants and minor reaction products): hydrocarbon fuel $+\mathrm{O}_{2} \rightarrow \mathrm{CO}_{2}+\mathrm{H}_{2} \mathrm{O}$. Clearly, carbon dioxide is an inherent product of the combustion of any carbon-containing fuel so to avoid carbon dioxide emissions the use of carbon-based fuels needs to cease and/or emissions must be captured and either sequestered or used in other processes.

To comprehensively address energy-related environmental impacts, the entire life cycle of a product or process must be considered, from acquisition of energy and material resources, to utilization and ultimate disposal (see Figure 3). Such an approach is provided by life cycle assessment (LCA), which allows environmental issues to be quantified and related to the part of the life cycle responsible for them [46]. LCA methodologies have been developed by the International Organisation for Standardisation (e.g., ISO 14040 Life Cycle Assessment - Principles and Guidelines), and typically involve three main steps: (1) inventory assessment, where environmental burdens associated with a product or process are identified and quantified in terms of resources drawn from and wastes released to the environment; (2) impact assessment, where the environmental stresses of the factors from the inventory assessment are quantified; and (3) improvement assessment, where opportunities for environmental improvements are identified, evaluated and prioritized in terms of need and benefit, including contributions to sustainability. LCAs have been performed for various energy activities, e.g., processes involving natural gas, nuclear power, hydrogen, and solar and wind energy [47-49]. Many of these studies demonstrate the environmental benefits of hydrogen as an energy carrier and non-fossil energy source. 
Figure 3. Scope of life cycle assessment of a product or process. Storage is not shown, but can occur in any of the steps. Material wastes can be gaseous, liquid and solid.

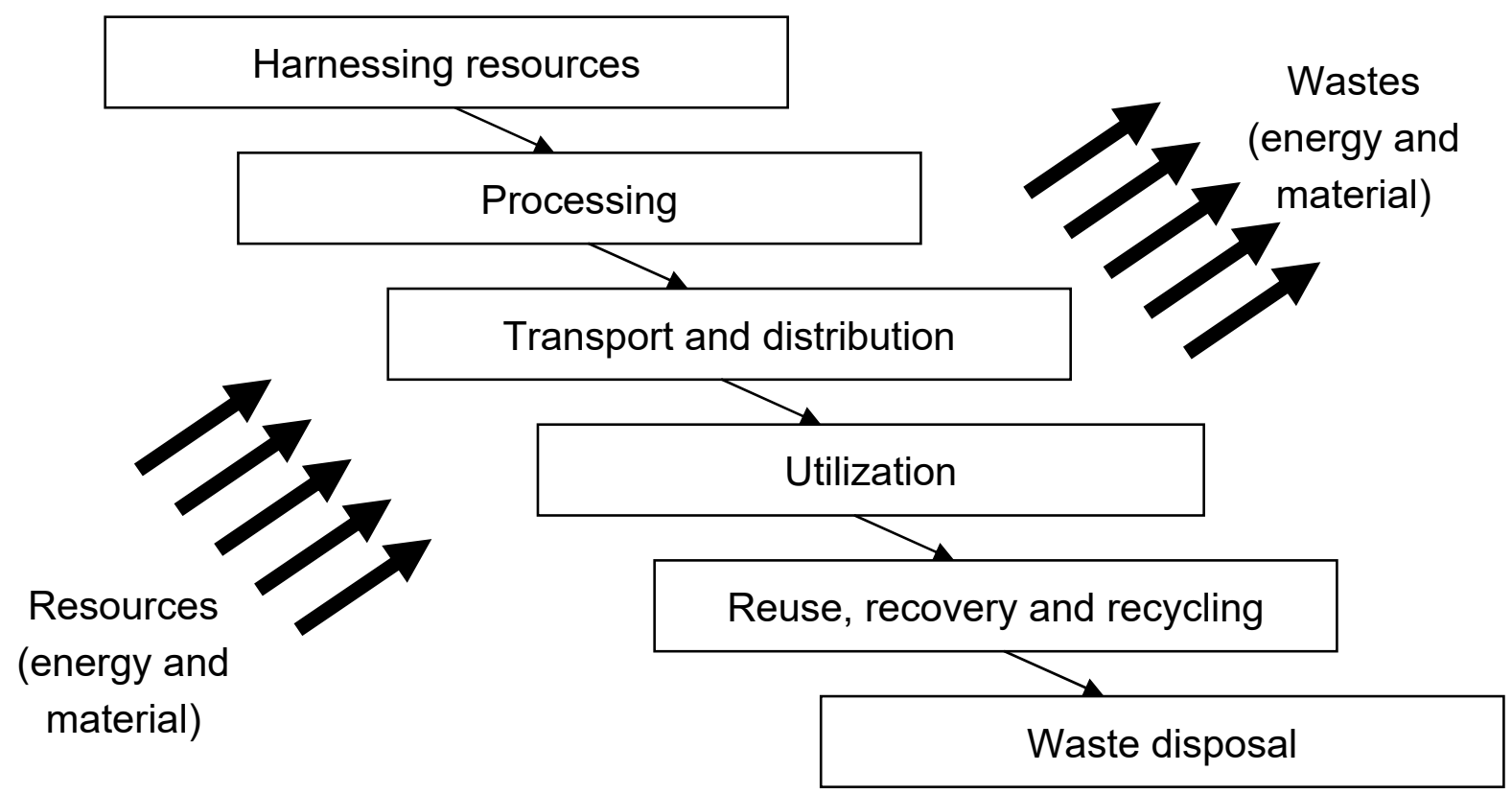

\subsection{Improve Socioeconomic Acceptability}

Many socioeconomic sustainability factors relate to energy, and consequently need to be considered in approaches to energy sustainability. These factors often are linked to the previously described sustainability approaches, e.g., harnessing sustainable energy sources must account for economics, global stability and geographic and intergenerational equity to maintain a sustainability focus. Many have discussed energy systems by considering them as socio-technical arrangements with strong interrelations of technological and social elements such as institutions, regulations, cultural values, social practices as well as interests, expectations and relationships of the actors involved [50]. Others have investigated socio-technical factors by considering energy transitions to sustainability, and examined the experiences with such transitions of countries that have introduced energy transition policies, e.g., the Netherlands [51,52]. This research has sought to identify barriers to energy transitions, different routes a transition can take and the policy and institutional settings that support such transitions. Some energy-related socioeconomic sustainability factors follow:

- Community involvement and social acceptability. People and communities must be involved in energy-related decisions if energy sustainability is to be attained, as the support of these groups is critical to success of any initiatives, and such support almost always requires consultation and involvement in decision making. A culture of sustainability can evolve when a consultative and collaborative approach is consistently followed.

- Economic affordability and equity. To be sustainable, energy services required to provide basic needs must be economically affordable by all societies and people. It is noted that some energy initiatives affordable at present, e.g., some efficiency improvement and environmental mitigation measures can be implemented in ways that save money over time. All societies need 
to be able to access energy resources, regardless of geographic location, to achieve energy sustainability. These ideas imply a need for equity among developed and developing countries in terms of energy opportunities. Sustainable energy options need to account for population growth since it places stresses on the environment and the carrying capacity of the planet. Also, energy sustainability requires that future generations be able to access energy resources. Equity in terms of energy is somewhat time dependent, and this author expects that short-term differences will diminish in time and energy opportunities in different countries will converge in the longer term.

- Lifestyles. Modifying lifestyles and tempering desires that are energy-driven can contribute to energy sustainability. Given that aspirations of people tend to increase continually, addressing this factor is often challenging. Transforming behavioural and decision-making patterns requires recognition that current development paths are not sustainable, but such recognition usually occurs only when significant short-term consequences are exhibited, e.g., oil-price shocks, disasters, droughts. To obtain the investments needed to reduce the risks associated with energy initiatives, the public must perceive the long-term consequences associated with present behaviour. Thus, an immediate and difficult challenge for policy makers is translating future threats associated with energy use into near-term priorities.

- Land use and aesthetics. The use of land for energy-related activities must be balanced with other needs, such as agriculture and recreation. This trade off is a particularly significant challenge with technologies like hydraulic energy, which often involves flooding large tracts of land, electricity transmission, which often traverses sensitive ecosystems, wind turbines, which are highly visible, and bioenergy, which often involves the growth of energy plants on land that could be used for other purposes. The aesthetics of the environment affect the well-being of people, making it an important aspect of sustainability. Avoiding damage to environmental aesthetics can be challenging, e.g., renewable energy technologies like solar collectors and wind turbines are considered by many to be detrimental to landscapes.

\section{Illustrations}

To demonstrate the concepts and approaches to energy sustainability presented in this article, several illustrations, which provide examples of practical sustainable energy options, are presented and compared.

\subsection{Thermal Energy Storage}

A thermal energy storage (TES) is a device which receives and holds thermal energy (heat or cold) until it is required. TES is particularly beneficial when a mismatch exists between times of energy supply and demand. As an example, consider an insulated thermal storage tank containing water (Figure 4). During the charging process, $1000 \mathrm{~kJ}$ of heat is transferred from an external hot fluid entering at $70^{\circ} \mathrm{C}$ through a heat exchanger to the storage, raising its temperature. After a period of storage, a discharging period occurs in which $800 \mathrm{~kJ}$ of heat is recovered from the storage through a heat exchanger using a heat recovery fluid, raising its temperature from $20^{\circ} \mathrm{C}$ to $35^{\circ} \mathrm{C}$. The TES energy 
efficiency, evaluated as the ratio of the heat recovered from the storage to the heat injected, is 800 $\mathrm{kJ} / 1000 \mathrm{~kJ}=80 \%$.

Figure 4. A thermal energy storage operation, showing its three main stages.
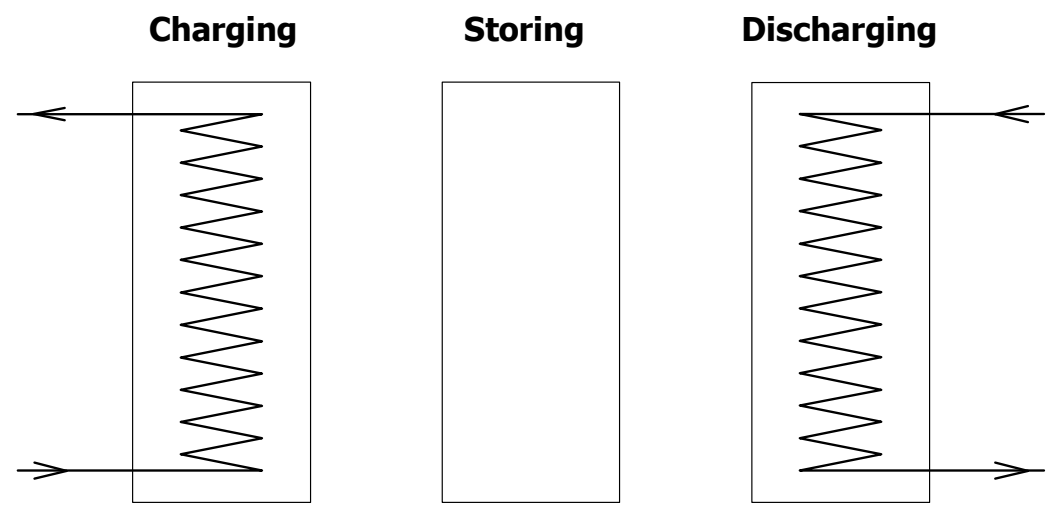

The use of TES systems often facilitates the utilization of sustainable energy resources, which are often intermittent. Some other benefits of TES [39,40,53] follow:

- reduced energy consumption and conservation of fossil fuels (by facilitating more efficient energy use and/or fuel substitution),

- reduced pollutant emissions $\left(\mathrm{CO}_{2}, \mathrm{SO}_{2}, \mathrm{NOx}, \mathrm{CFCs}\right.$, etc.),

- reduced costs (energy, initial and maintenance), and

- more efficient utilization of equipment and energy.

Thus, thermal energy storage can contribute significantly to more efficient, environmentally benign energy use [39]. Applications include building heating and cooling and electric power generation and distribution. TES can reduce aggregate emissions at power plants significantly, e.g., TES systems have been shown to reduce $\mathrm{CO}_{2}$ emissions in the United Kingdom by $14 \%$ to $46 \%$ by shifting electric load to off-peak periods [54]. Also, an EPRI co-sponsored study estimated $\mathrm{CO}_{2}$ emissions reductions of 7\% with TES compared to conventional electric cooling technologies [55]. TES was shown to be able to mitigate annual emissions of about 560 tons of $\mathrm{NO}_{\mathrm{x}}$ and 260,000 tons of $\mathrm{CO}_{2}$ in California, using California Energy Commission data indicating that existing gas plants produce about $0.06 \mathrm{~kg}$ of $\mathrm{NO}_{\mathrm{x}}$ and $15 \mathrm{~kg}$ of $\mathrm{CO}_{2}$ per 293,100 $\mathrm{kWh}$ of fuel burned and assuming that TES installations save an average of $6 \%$ of the total cooling electricity needs [56].

\subsubsection{Underground thermal energy storage}

Thermal energy storage devices come in many types (e.g., tanks, aquifers, ponds, caverns). Many such systems store heat or cold in the ground, exploiting the thermal capacity of soils and other underground materials, and the near constant temperatures below the surface. Such systems take advantage of the abundant and natural existence of thermal energy storage potential in the ground. For 
instance, a large underground thermal energy storage is located at the University of Ontario Institute of Technology in Oshawa, Ontario, Canada (Figure 5). The university's borehole thermal energy storage system contains 384 holes, each 213 metres deep. This TES is part of a larger energy system at the university, as described subsequently. Large-scale thermal storage systems have also been implemented at Stockton College in New Jersey and in Sweden. Other underground TES applications exist in Canada, e.g., Scarborough Centre in Toronto, Carleton University in Ottawa, the Sussex Hospital in New Brunswick and Pacific Agricultural Centre in Agassiz, British Columbia. These systems help improve energy sustainability, in manners suitable to their jurisdictions.

Figure 5. The borehole thermal energy storage system at University of Ontario Institute of Technology, showing the grid of underground boreholes and several university buildings.

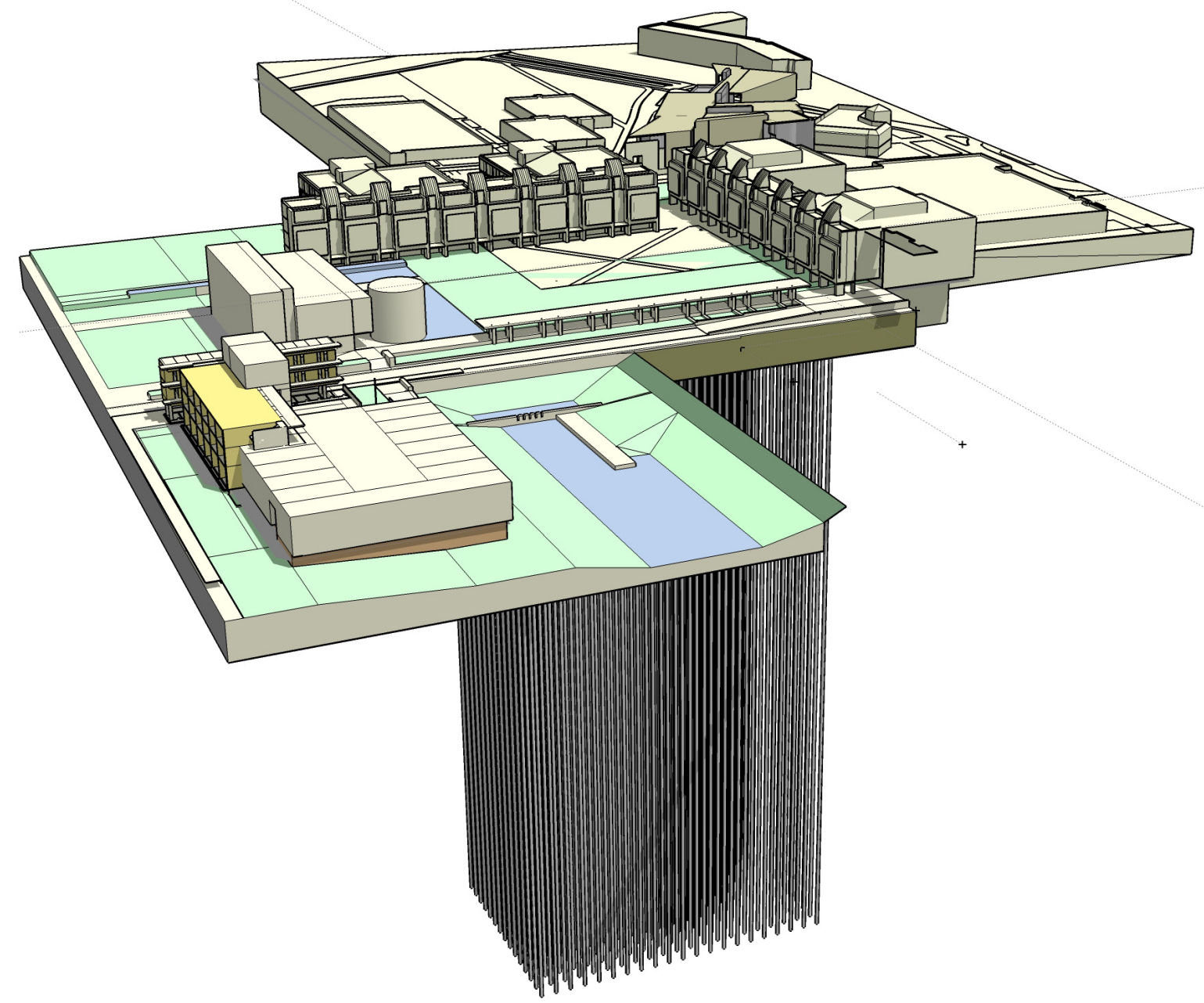

\subsubsection{Integrating thermal energy storage with solar energy}

TES systems have been employed to facilitate the use of solar energy in integrated systems, by allowing solar energy to be converted to thermal energy and held until needed for building space heating or heating domestic hot water or other purposes. Such systems facilitate the use of solar energy and thereby reduce environmental impact and contribute significantly to energy sustainability. 


\subsubsection{Seasonal thermal energy storage}

The storage duration for thermal energy storage can vary from as short as daily to seasonal or annual. In the latter case, systems have been devised and operated that collect and store heat or cold during one season for use in another when it is needed, providing a significant option for energy sustainability.

For example, cold seasonal storage systems have been developed that collect winter cold by creating ice in a large, insulated storage vessel during winter days when the ambient temperature is below the freezing point of water. Then, the ice is used to provide air conditioning during the summer, effectively allowing winter cold to be used for "free" summer air conditioning.

Alternatively, seasonal storage systems for heating capacity have been developed that work in conjunction with solar thermal collectors. Such systems capture solar energy throughout the year, but particularly in summer when sunshine tends to be abundant, and allow it to be used for heating buildings during the winter and at other times when heating is needed.

\subsection{Heat Pumps}

A heat pump uses electricity to extract heat from a low-temperature region (e.g., ground, air, aquifer) and to deliver it to a region of higher-temperature for heating. A basic heat pump contains four main devices (evaporator, compressor, condenser, expansion throttling valve) as well as associated piping, valves and controls. Heat pumps are highly efficient. For illustration, consider space heating with a heat pump that extracts heat from the nearby soil at $278 \mathrm{~K}$ and provides it for space heating at $308 \mathrm{~K}$. If a simple electric resistance heater, which converts electricity to heat at a temperature suitable for space heating, is used for the space heating operation, the quantity of energy supplied is approximately equal to the thermal energy delivered, since the energy efficiency of an electric heater is nearly $100 \%$. But for a heat pump with a typical "coefficient of performance" (COP), which is the ratio of product thermal energy delivered to electrical energy used to drive the heat pump, of four, about $25 \%$ of the electricity is required compared to electric resistance heating, to provide the same heating product. Note that exergy has been used in heat pump assessments to better understand their efficiencies and losses by many researchers, e.g., [33,57-59].

Heat pump technologies (for heating and air conditioning) have been identified as having the potential to play a major role in reducing energy consumption and the carbon footprint in the building sector [60,61], which usually includes residential, public administration, commercial, and other institutional buildings. The principal types of processes occurring in the devices and systems comprising the building sector include a significant quantity of electric and fossil fuel heating. For example, energy end-use for the residential and commercial sectors in Canada is broken down in Table 5 [62,63]. The Canadian building sector (commercial, institutional and residential) accounts for $31 \%$ of total secondary energy use and $28 \%$ of greenhouse gas emissions. Space heating dominates, accounting for over $50 \%$ of this energy use and a similar proportion of the greenhouse gas emissions. Also, the demand for air conditioning is significant and has in recent decades increased greatly (by 80\% since 1990), likely due to increased living standards and higher internal heat gains in buildings, and may become greater in the future due to climate change effects. Heat pump technologies allow heating efficiencies to be increased not just incrementally, but by over three to four times compared to 
conventional oil and gas boilers. Clearly, the ability of heat pumps to markedly reduce energy use for space and water heating offers an important option for energy sustainability in Canada.

Table 5. Breakdown by type of energy use in the residential and commercial sectors data of Canada.

\begin{tabular}{lccc}
\hline \multicolumn{1}{c}{ Process } & \multicolumn{3}{c}{ Energy use (\%) } \\
\cline { 2 - 4 } & Electrical & Fuel & All energy forms \\
\hline Space heating & 15.0 & 79.5 & 66.0 \\
Water heating & 14.0 & 15.0 & 10.0 \\
Cooking & 5.0 & 4.5 & 1.7 \\
Clothes drying & 5.0 & 1.0 & 1.3 \\
Others* & 61.0 & 0.0 & 21.0 \\
Total & 100.0 & 100.0 & 100.0 \\
\hline
\end{tabular}

* Includes material moving (fans, pumps), cooling (air conditioners, refrigerators, freezers), cleaning (washers, dryers, dishwashers), lighting, etc.

\subsubsection{Ground-source heat pumps}

Ground-source heat pumps (GSHPs) are a rapidly growing heat pump technology that can be applied widely to help make energy systems sustainable [64]. GSHPs utilize renewable energy, the energy contained in the ground near the surface which is an indirect result of solar energy. This energy is upgraded by the heat pump for heating, i.e., heat is taken from the ground at low temperature and transferred at a higher temperature to the building. Alternatively the ground can absorb energy by using the heat pump in its cooling (reverse) mode. GSHPs provide reliable and low-cost energy services like heating and cooling, and improve the utilization of electricity and other fuels. In countries with significant climate variations from summer to winter, the cold outdoor winter conditions make ground-source heat pumps an advantageous technology for meeting heating loads with high efficiencies during the entire cold season. GSHPs thus form an important component in the portfolio of technologies for highly efficient buildings (e.g., net-zero energy buildings).

As an illustration, consider the situation in Canada. A recent study shows that the renewable energy content when using GSHPs in the heating mode may be as high as $65 \%$ depending on location, displacing the needs for primary fuels like oil and gas [60]. Compared to natural gas heating systems, GSHPs were shown to be able to reduce greenhouse gas emissions in the residential sector by up to $96 \%$ and in small office buildings by up to $75 \%$ [60]. However, the Canadian market remains largely untapped, with only 3150 units installed in 2006 according to a recent survey by the Canadian GeoExchange Coalition [65]. If the penetration rate of ground source heat pumps for air heating and hot domestic water in Canada were two per cent per year, after five years the annual savings would be $120 \mathrm{PJ}$ of energy and 6.5 megatonnes equivalent of $\mathrm{CO}_{2}$.

GSHPs have gained significant market shares in other countries, including Japan, Sweden and other countries with similar climatic conditions. For instance, approximately 300,000 GSHPs are installed in Sweden with an annual growth rate of 30,000 units. The systems delivered $16 \%$ of all space heating of Sweden in 2000 and this percentage will likely increase to $27 \%$ in 2010. 


\subsubsection{Integrating thermal energy storage with ground-source heat pumps}

Thermal energy storage can be integrated with GSHPs advantageously, so as to improve the contribution to energy sustainability made be either separately. Such integration offers long-term (seasonal) storage capabilities, i.e., storing summer heat for winter heating or storing winter cold for summer air conditioning, and can be integrated with intermittent energy sources (e.g., several renewable energy technologies, waste heat).

For instance, the borehole thermal energy storage system at the University of Ontario Institute of Technology described earlier provides the basis for a highly efficient and environmentally friendly and low cost heating and cooling system, capable of servicing the university's buildings. The geothermal well field is the central component in the borehole thermal energy storage system. A glycol solution, encased in polyethylene tubing, circulates through an interconnected, underground network. During the winter, fluid circulating through tubing extended into the wells collects heat from the earth and carries it into the buildings. In summer, the system will reverse to pull heat from the building and place it in the ground. Thus the borehole thermal energy storage provides for both heating and cooling on a seasonal basis. The system is one of the largest geothermal well fields in North America.

\subsection{Cogeneration and Trigeneration}

Cogeneration is the simultaneous production of thermal and electrical energy, typically using significantly less energy resources than required to produce the same thermal and electrical products in separate processes, thereby providing a significant contribution to energy sustainability. Trigeneration is an expanded form of cogeneration in which electricity, heat and cold are simultaneously produced $[66,67]$. Thermal power plants form the basis of most cogeneration systems. In thermal power plants, a fuel is converted to heat in the form of steam or hot gases, which is subsequently converted to mechanical energy and then to electricity $[68,69]$. Approximately $25 \%$ to $50 \%$ of the heat is converted to electricity, with the remainder rejected as waste to the environment. Cogeneration systems are similar to thermal power plants, but some of the generated heat is delivered as a product in such forms as steam or hot water, usually with a sacrifice in electricity production. For instance, in steam turbinebased cogeneration system, steam is extracted from one or more points on the turbines and exported to nearby heat users, or the steam passes through part of the steam turbines and is then diverted for use in heating. In steam turbine-based cogeneration, the waste heat rejection is reduced, allowing overall cogeneration efficiencies based on both the electrical and thermal energy products of over $80 \%$ to be achieved [70]. Exergy assessments of cogeneration for buildings, aimed at improving efficiency, have been reported [71,72].

Two main categories of heat demands can normally be satisfied through cogeneration: residential, commercial and institutional processes (e.g., space and water heating), which require large quantities of heat at relatively low temperatures [73], and industrial processes (e.g., drying, heating, boiling), which require heat at a wide range of temperatures. Thermal energy-intensive industries are numerous and include chemical, petrochemical and metal processing, fertilizer and cement production, manufacturing and construction, pulp and paper processing. Cogeneration can be implemented in a distributed manner or centrally [74]. The use of a central heat supply to meet the heat demands of the building sector is often referred to as district heating, and has been applied extensively. It is noted that 
cogenerated heat can even be used to drive absorption chillers for space cooling, rather than using more conventional electrically driven chillers.

Cogeneration can be applied in plants of varying sizes, ranging from those for single buildings to utility-scale facilities. For the latter case, the present author carried out a detailed study for Ontario, the largest province in Canada [70]. Some important regional and utility-sector results from that study are highlighted in Table 6 for several penetration scenarios. The implications of these findings are significant. For the region, electricity consumption decreases by between 5\% for low penetration of utility-based cogeneration and $30 \%$ for high penetration, thereby permitting regional electrical generation to decrease by correspondingly, and emissions of carbon dioxide, a principal greenhouse gas, decrease by $4 \%$ to $15 \%$, demonstrating that utility-based cogeneration can contribute significantly to mitigating global warming and, subsequently, climate change. For the electrical-utility sector, utility-based cogeneration permits reductions of $20 \%$ to $40 \%$ in coal use and coal-related emissions, $7 \%$ to $35 \%$ in uranium use and related emissions, and $20 \%$ to $40 \%$ in carbon dioxide emissions. The case study consequently suggests that electrical utility-based cogeneration in a region could be beneficial in that, for the same services delivered, cogeneration permits increased efficiency and reduced energy consumption and related emissions, and can increase the utilization of nuclear energy by substituting it for other fuels.

Table 6. Percentage reductions in key parameters for Ontario, Canada and its electricalutility sector.

\begin{tabular}{lccccc}
\hline & \multicolumn{2}{c}{ Regional parameters } & \multicolumn{3}{c}{ Electrical-utility sector parameters } \\
\cline { 2 - 6 } $\begin{array}{c}\text { Cogeneration } \\
\text { penetration }\end{array}$ & $\begin{array}{c}\text { Electricity } \\
\text { consumption }\end{array}$ & $\begin{array}{c}\mathrm{CO}_{2} \\
\text { emissions }\end{array}$ & $\begin{array}{c}\text { Coal } \\
\text { use }\end{array}$ & $\begin{array}{c}\text { Uranium } \\
\text { use }\end{array}$ & $\begin{array}{c}\mathrm{CO}_{2} \\
\text { emissions }\end{array}$ \\
\hline Low & 5 & 4 & 20 & 7 & 20 \\
High & 30 & 15 & 40 & 35 & 40 \\
\hline
\end{tabular}

Cogeneration is clearly a technology that contributes to sustainability by improving efficiency and thereby reducing environmental impact. In addition, it generates non-fossil energy carriers (thermal and electrical energy).

\subsection{Thermochemical Hydrogen Production}

Thermochemical water decomposition uses thermal energy to drive a series of chemical reactions that lead to the net result of water splitting: $\mathrm{H}_{2} \mathrm{O} \rightarrow \mathrm{H}_{2}+1 / 2 \mathrm{O}_{2}$ [43-45]. The primary advantage of thermochemical cycles is that they split water with lower temperatures than required to split water directly through heating. The advantages of a cycle increase as its required peak temperatures are reduced, as a greater range of heat sources can then be considered and energy sustainability objectives can better be achieved. Research on thermochemical production of hydrogen has increased recently from its beginnings in the 1970s [75,76]. Most preliminary designs of thermochemical hydrogen production are based on nuclear or solar energy, providing different sustainable options. In the near term, thermochemical hydrogen production is likely to be based on nuclear energy, offsetting fossil fuels. Various existing and new nuclear reactor concepts are being considered [76-79]. A review of 
more than 100 thermochemical cycles identified promising cycles for efficient, cost-effective, largescale production of hydrogen utilizing high-temperature heat from an advanced nuclear power station. Thermochemical hydrogen production from nuclear energy is under development in many countries [76]. Research on coupling with Canada's future nuclear reactors is ongoing, while Sandia National Laboratory in the U.S. and the Atomic Energy Commission (CEA) in France are developing a hydrogen pilot plant with a sulphur-iodine (S-I) cycle. The Japan Atomic Energy Agency plans a S-I plant to produce $60,000 \mathrm{~m}^{3} / \mathrm{hr}$ of hydrogen in 2020, and bench-scale tests have been carried out. The Korea Atomic Energy Research Institute (KAERI) is collaborating with China to produce hydrogen with the HTR-10 reactor. Several countries are participating in the Generation IV International Forum to develop technologies for cogeneration of hydrogen by high-temperature thermochemical cycles and electrolysis. Research has been carried out to lower the peak temperatures required, and cycles have been investigated that require lower peak temperatures, like the copper-chlorine $(\mathrm{Cu}-\mathrm{Cl})$ thermochemical cycle [80-82], which requires heat at approximately $550^{\circ} \mathrm{C}$ and has been identified by Atomic Energy of Canada Ltd. as highly promising (see Figure 6).

Figure 6. Simplified diagram of a copper-chlorine thermochemical water decomposition cycle for hydrogen production. High-temperature heat is input to the oxygen production, hydrogen production and $\mathrm{HCl}$ production steps.

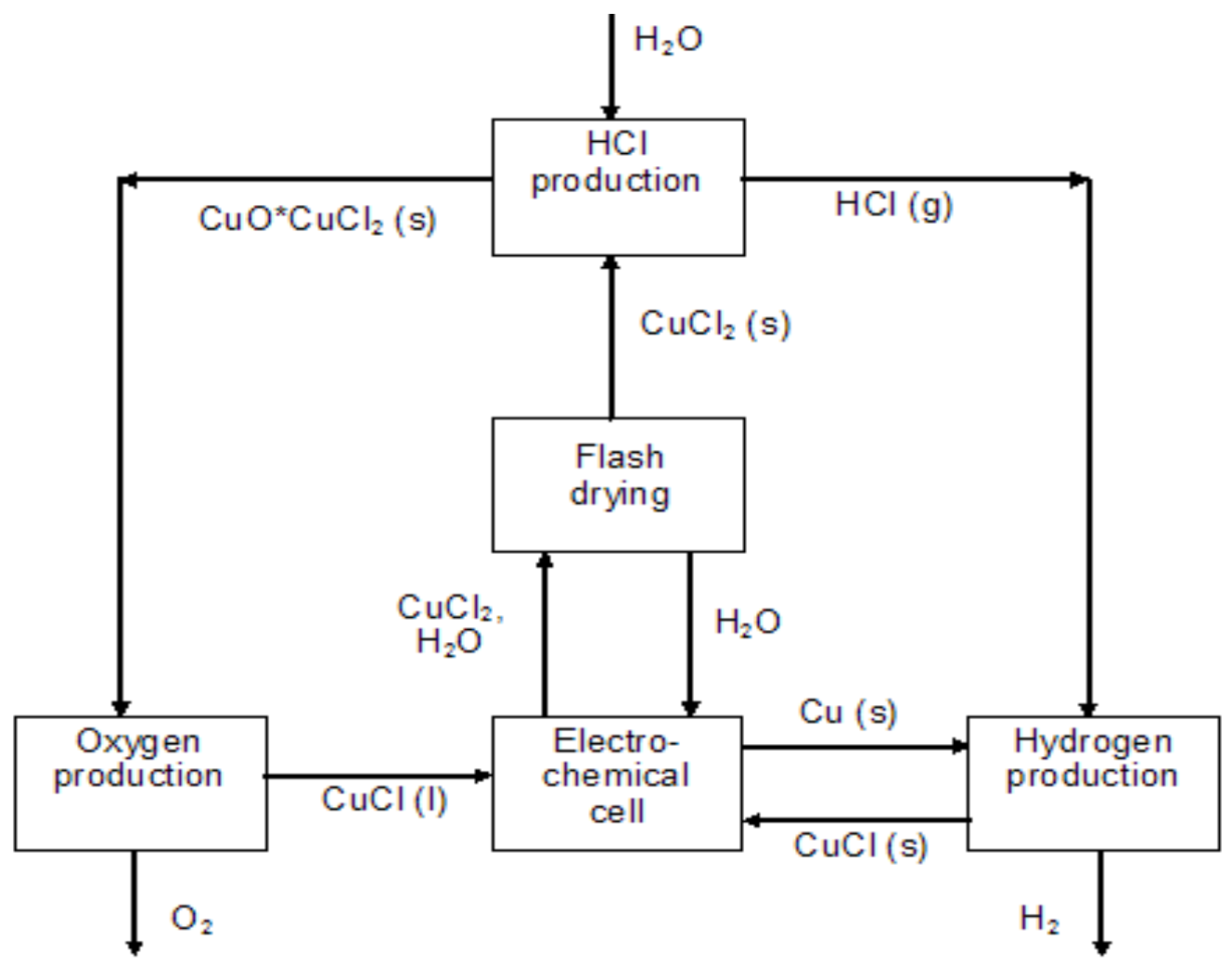

In the longer term, thermochemical hydrogen production is likely to be based on solar energy. Thermochemical hydrogen production using concentrated solar radiation as the source of hightemperature heat have been investigated [44,78,83], e.g., a cycle using $\mathrm{Zn} / \mathrm{ZnO}$ redox reactions [84] and the S-I cycle and a hybrid S cycle (the Westinghouse cycle) [78].

By producing sustainable energy carriers to facilitate the use of sustainable energy resources, thermochemical water decomposition can contribute significantly to energy sustainability, and 
illustrates many of the concepts in this article. By producing hydrogen energy, the process yields a useful chemical fuel that complements electricity and can be used to produce hydrogen-derived fuels (e.g., ammonia, methanol). In addition, thermochemical water decomposition permits increased efficiency and environmental advantages. The efficiency of producing hydrogen by thermochemical water decomposition is suggested by many to exceed the efficiency of other hydrogen production processes that have similar sustainability characteristics. Efforts to improve the efficiency of thermochemical hydrogen production using exergy analysis have been carried out. The results of one such study [43] showed that exergy analysis indicates that internal exergy consumptions should be reduced to increase efficiency, while energy analysis indicates erroneously that quantities of waste effluents should be reduced (see Table 7). The reduced environmental impacts achievable with thermochemical hydrogen production can be better understood with life cycle assessment, which has been reported for nuclear-driven versions of the copper-chlorine thermochemical cycle [85] and the Ispra Mark 9 thermochemical cycle [86].

Table 7. Energy and exergy balances for hydrogen production with the Ispra Mark-10 thermochemical water decomposition process.

\begin{tabular}{lcc}
\hline \multicolumn{1}{c}{ Flow } & Energy (\% of input energy) & Exergy (\% of input exergy) \\
\hline Inputs (high-temp. heat, water) & 100.0 & 100.0 \\
Products (hydrogen; potential by- & 20.5 & 25.0 \\
product oxygen is neglected) & & \\
Losses & 79.5 & 74.5 \\
External (waste emissions) & 79.5 & 4.5 \\
Internal (consumptions) & - & 70.0 \\
Total products and losses & 100.0 & 100.0 \\
\hline
\end{tabular}

\subsection{Potential Contributions to Energy Sustainability of the Illustrative Examples}

The examples considered in this section illustrate many of the energy-sustainability concepts in this article (harnessing sustainable energy sources, utilizing sustainable energy carriers, increasing efficiency, reducing environmental impact and improving socioeconomic acceptability). The contributions of the illustrative examples to energy sustainability, in terms of these concepts, are discussed here.

- Sustainable energy sources. Some of the examples considered help improve the utilization of sustainable energy sources and enhance energy-resource flexibility. Ground-source heat pumps produce useful heat partly by exploiting the energy in the ground, which is often referred to as a type of renewable energy. The thermochemical hydrogen production process considered here is designed to utilize non-fossil and sustainable energy resources (nuclear and solar energy). Thermal energy storage facilitates the use of sustainable energy systems but providing a buffer between times of energy availability and need, which is important for the success of intermittent renewable energy resources. 
- Sustainable energy carriers. All of the examples produce or involve the use of sustainable and beneficial energy carriers. For instance, heat pumps produce useful heat, while cogeneration produces useful heat and electricity. Trigeneration produces heat, cold and electricity, while thermal energy storage assists the use of heat and cold. Thermochemical water decomposition produces hydrogen energy, a useful chemical fuel that complements electricity. Using the appropriate energy carrier for the corresponding energy demand helps enhance energy sustainability.

- Efficiency. Some of the illustrations involve technologies that greatly improve the efficiency with which energy resources are used and energy services are provided. Heat pumps and cogeneration are particularly noteworthy in this regard. Heat pumps allow heating to be provided with $15 \%$ to $25 \%$ of the energy that would otherwise be required to provide an equivalent amount of heat. Cogeneration allows electricity and thermal energy to be produced with $10 \%$ to $40 \%$ less energy resources than would be required to produce the same electricity and thermal energy in separate processes. Efforts to improve the efficiency and to integrate the examples more efficiently into society's energy systems can also be aided by exergy analysis, which has been applied for some of the illustrations considered. The effectiveness of efficiency measures, in light of such factors as energy rebound, needs to be verified through practical demonstrations and other means.

- Environmental impact. The examples all lead to improved environmental performance in different ways, often for the reasons described in the previous three points. They address two key aspects of reducing environmental impact related to energy (appropriate resources/carriers and efficiency), and thereby enhance energy sustainability.

- Socioeconomic acceptability. Many socioeconomic factors are affected beneficially by the illustrations. For instance, many of the illustrative technologies considered are economically advantageous presently (e.g., heat pumps and cogeneration), improving affordability and equity and therefore enhancing energy sustainability.

\section{Conclusions}

A pragmatic approach is utilized to demonstrate that several crucial factors need to be addressed appropriately to achieve energy sustainability, and thereby allow it to contribute to sustainable development. The key factors include harnessing sustainable energy sources, utilizing sustainable energy carriers, increasing efficiency, reducing environmental impact and improving socioeconomic acceptability (e.g., community involvement, economic affordability, equity, lifestyles, land use, aesthetics). Furthermore, the use of advanced tools like exergy analysis for efficiency improvement and life cycle analysis for environmental enhancement are shown to offer significant advantages in efforts to achieve energy sustainability. The numerous examples considered illustrate the concepts presented in the article. The results suggest that considering these key factors can help identify, develop and implement options and routes for energy sustainability, which correspondingly can facilitate a broader societal shift towards overall sustainability. The results are widely applicable since energy use and its impacts on the environment are global concerns, and potentially of great consequence given the importance of energy in economic development and living standards. 


\section{Acknowledgements}

Financial support was provided by the Natural Sciences and Engineering Research Council of Canada, and is gratefully acknowledged.

\section{References and Notes}

1. Rosen, M.A. Towards Energy Sustainability: A Quest of Global Proportions. Forum on Public Policy Online: A Journal of the Oxford Round Table 2009, Summer 2008 edition, 1-20.

2. Lior, N. Energy resources and use: The present situation and possible paths to the future. Energy 2008, 33, 842-857.

3. Ontario Power Authority. Ontario's Integrated Power System Plan: Scope and Overview. Report, 29 June 2006.

4. Rosen, M.A. Natural energy versus additional energy. In Encyclopedia of Energy Engineering and Technology; Capehart, B.L., Ed.; Taylor \& Francis: New York, USA, 2007; pp. 1088-1095.

5. World Commission on Environment and Development. Our Common Future; Oxford University Press: Oxford, UK, 1987.

6. Haberl, H. The global socioeconomic energetic metabolism as a sustainability problem. Energy 2006, 31, 87-99.

7. Rosen, M.A. Energy efficiency and sustainable development. Int. J. Global Energy Issues 2002, 17, 23-34.

8. Goldemberg, J.; Johansson, T.B.; Reddy A.K.N.; Williams, R.H. Energy for a Sustainable World; Wiley: New York, USA, 1988.

9. Niele, F. Energy: Engine of Evolution; Elsevier: Oxford, UK, 2005.

10. Wall, G.; Gong, M. On exergy and sustainable development. Exergy, An International Journal 2001, 1, 128-145, 217-233.

11. Zvolinschi, A.; Kjelstrup, S.; Bolland, O.; van der Kooi, H. J. Exergy sustainability indicators as a tool in industrial ecology. Journal of Industrial Ecology 2007, 11, 85-98.

12. Hennicke, P.; Fischedick, M. Towards sustainable energy systems: The related role of hydrogen. Energy Policy 2006, 34, 1260-1270.

13. Dunn, S. Hydrogen futures: toward a sustainable energy system. Int. J. Hydrogen Energy 2002, 27, 235-264.

14. World Energy Assessment Overview: 2004 Update; Johansson, T.B., Goldemberg, J., Eds.; United Nations Development Programme: New York, USA, 2004.

15. Ayres, R.U.; Turton, H.; Casten, T. Energy efficiency, sustainability and economic growth. Energy 2007, 32, 634-648.

16. Cleveland, J. Advanced plants to meet rising expectations for nuclear power. Int. J. Global Energy Issues 2008, 30, 393-412.

17. Toth, F.L. Prospects for nuclear power in the 21 st century: a world tour. Int. J. Global Energy Issues 2008, 30, 1-4, 3-27.

18. Rogner, H.-H.; McDonald, A.; Riahi, K. Long-term performance targets for nuclear energy. Part 1: The global scenario context. Int. J. Global Energy Issues 2008, 30, 1-4, $28-76$. 
19. Rogner, H.-H.; McDonald, A.; Riahi, K. Long-term performance targets for nuclear energy. Part 2: Markets and learning rates. Int. J. Global Energy Issues 2008, 30, 1-4, 77-101.

20. Scott, D.S. Smelling Land: The Hydrogen Defense Against Climate Catastrophe; Canadian Hydrogen Association: Ottawa, Canada, 2007.

21. Marban, G.; Valdes-Solis, T. Towards the hydrogen economy? International Journal of Hydrogen Energy 2007, 32, 1625-1637.

22. Penner, S.S. Steps toward the hydrogen economy. Energy 2006, 31, 33-43.

23. Dalcor Consultants Ltd. and Intuit Strategy Inc. Canadian Hydrogen: Current Status and Future Prospects; Natural Resources Canada, Ottawa, 2004.

24. Lattin, W.C.; Utgikar, V.P. Transition to hydrogen economy in the United States: A 2006 status report. Int. J. Hydrogen Energy 2007, 32, 3230-3237.

25. Arnason, B.; Sigfusson, T.I. Iceland-A future hydrogen economy. Int. J. Hydrogen Energy 2000, 25, 389-394.

26. Yildiz, B.; Kazimi; M.S. Efficiency of hydrogen production systems using alternative energy technologies. Int. J. Hydrogen Energy 2006, 31, 77-92.

27. Sigfusson, T.I. Pathways to hydrogen as an energy carrier. Phil. Trans. R. Soc. A 2007, 365, 1853, 1025-1042.

28. Marchetti, C. Long-term global vision of nuclear-produced hydrogen. Int. J. Nuclear Hydrogen Production and Applications 2006, 1, 13-19.

29. Soutworth, F.; Gauthier, J.-C.; Lecomte, M.; Carre, F. Potential applications for nuclear energy besides electricity generation: AREVA global perspective of HTR potential market. Proc. Conf. on Advanced Nuclear Fuel Cycles and Systems; Boise, Idaho, 9-13 Sept. 2007; pp. 1563-1574.

30. Madlener, R.; Alcott, B. Energy rebound and economic growth: A review of the main issues and research needs. Energy 2009, 34, 370-376.

31. Dimitropoulos, J. Energy productivity improvements and the rebound effect: An overview of the state of knowledge. Energy Policy 2007, 35, 6354-6363.

32. Hanley, N.; McGregor, P.G.; Swales, J.K.; Turner, K. Do increases in energy efficiency improve environmental quality and sustainability? Ecological Economics 2009, 68, 692-709.

33. Dincer, I.; Rosen, M.A. Exergy: Energy, Environment and Sustainable Development; Elsevier: Oxford, UK, 2007.

34. Szargut, J. Exergy Method: Technical and Ecological Applications; WIT Press: Southampton, UK, 2005.

35. Rosen, M.A.; Dincer, I.; Kanoglu, M. Role of exergy in increasing efficiency and sustainability and reducing environmental impact. Energy Policy 2008, 36, 128-137.

36. Rosen, M.A.; Dincer, I. Exergoeconomic analysis of power plants operating on various fuels. Applied Thermal Engineering 2003, 23, 643-658.

37. Sciubba, E. From engineering economics to extended exergy accounting: a possible path from monetary to resource-based costing. Journal of Industrial Ecology 2004, 8, 4, 19-40.

38. Jorgensen, S.E.; Svirezhev, Y.M. Towards a Thermodynamic Theory for Ecological Systems; Elsevier: Oxford, UK, 2004.

39. Dincer, I.; Rosen, M.A. Thermal Energy Storage Systems and Applications; Wiley: London, 2002. 
40. Dincer, I.; Rosen, M.A. Use of thermal energy storage for sustainable buildings. Proceedings of the Institution of Civil Engineers-Energy 2007, 160, 113-121.

41. Rosen, M.A.; Le, M.N.; Dincer, I. Efficiency analysis of a cogeneration and district energy system. Applied Thermal Engineering 2005, 25, 147-159.

42. Barclay, F.J. Fuel Cells, Engines and Hydrogen: An Exergy Approach; Wiley: New York, USA, 2006.

43. Rosen, M.A. 1990. Thermodynamic analysis of hydrogen production by thermochemical water decomposition using the Ispra Mark-10 cycle. In Hydrogen Energy Progress 8; Veziroglu, T.N., Takahashi, P.K., Eds.; Pergamon: Toronto, Canada; pp. 701-710.

44. Abanades, S.; Charvin, P.G.; Flamant Neveu, P. Screening of water-splitting thermochemical cycles potentially attractive for hydrogen production by concentrated solar energy. Energy 2006, 31, 2805-2822.

45. Orhan, M.F.; Dincer, I.; Rosen, M.A. Energy and exergy assessments of the hydrogen production step of a copper-chlorine thermochemical water splitting cycle driven by nuclear-based heat. Int. J. Hydrogen Energy 2008, 33, 6456-6466.

46. Graedel, T.E.; Allenby, B.R. Industrial Ecology, $2^{\text {nd }}$ Ed.; Prentice Hall: Upper Saddle River, NJ, USA, 2003.

47. Granovskii, M.; Dincer I.; Rosen, M.A. Exergetic life cycle assessment of hydrogen production from renewables. Journal of Power Sources 2007, 167, 461-471.

48. Utgikar, V.; Thiesen, T. Life cycle assessment of high temperature electrolysis for hydrogen production via nuclear energy. Int. J. Hydrogen Energy 2006, 31, 939-944.

49. Solli, C.; Stromman, A.H.; Hertwich, E.G. Fission or Fossil: Life Cycle Assessment of Hydrogen Production. Proceedings of the IEEE 2006, 94/10, 1785-1794.

50. Rohracher, H. Energy systems in transition: Contributions from social sciences. International Journal of Environmental Technology and Management 2008, 9, 144-161.

51. Verbong, G.; Geels, F. The ongoing energy transition: Lessons from a socio-technical, multi-level analysis of the Dutch electricity system (1960-2004). Energy Policy 2007, 35, 1025-1037.

52. Kemp, R.; Rotmans, J.; Loorbach, D. Assessing the Dutch energy transition policy: How does it deal with dilemmas of managing transitions? Journal of Environmental Policy \& Planning 2007, 9, 315-331.

53. Thermal Energy Storage for Sustainable Energy Consumption: Proceedings of the NATO Advanced Study Institute on Thermal Energy Storage for Sustainable Energy Consumption Fundamentals, Case Studies and Design; Paksoy, H.O., Ed.; NATO Science Series II: Mathematics, Physics and Chemistry, Springer: New York, USA, 2007.

54. Beggs, C.B. Ice thermal storage: impact on United Kingdom carbon dioxide emissions. Building Services Engineering Research and Technology 1994, 15, 1, 756-763.

55. Reindl, D.T. Characterizing the Marginal Basis Source Energy Emissions Associated with Comfort Cooling Systems. Thermal Storage Applications Research Center, Report TSARC 94-1, US, 1994.

56. California Energy Commission. Source Energy and Environmental Impacts of Thermal Energy Storage, Report P500-95-005, California, 1996. 
57. Rosen, M.A.; Tang R.; Dincer, I. Effect of stratification on energy and exergy capacities in thermal storage systems. Int. J. Energy Research 2004, 28, 177-193.

58. Canhoto, P.; Reis, A.H.; Miguel A.F.; Rosa, R. Utilisation of air-groundwater exergy potential for improvement of the performance of heat pump systems. Int. J. Exergy 2006, 3, 1-15.

59. Rosen, M.A.; Hamzeh, H. Empirical comparison of temperature-distribution models for energy and exergy analyses of stratified thermal energy storages. Int. J. Green Energy 2006, 3, 291-307.

60. Hanova, J.; Dowlatabadi, H. Strategic GHG reduction through the use of ground source heat pump technology. Environmental Research Letters 2007, 2, 4, paper 044001.

61. Spitler, J.D. Ground-source heat pump system research - past, present, and future. International Journal of HVAC\&R 2005, 11, 165-167.

62. Statistics Canada. Energy supply and demand: 2006. The Daily, 20 Dec. 2007.

63. Statistics Canada. Primary and secondary energy - Ontario. Tables 1-8 and 2-8 in Report on Energy Supply-Demand in Canada - 2006. Report 57-003-X, 3 June 2008.

64. Halozan, H. Ground-source heat pumps and buildings. Proc. 9th International IEA Heat Pump Conference; Zurich, 20-22 May 2008.

65. Canadian GeoExchange Coalition. Survey of Canadian geoexchange industry: 2004-2006, GeoConneXion Magazine 2007, December, 10-13.

66. Emho, L. District energy efficiency improvement with trigeneration: basic considerations and case studies. Energy Engineering: Journal of the Association of Energy Engineering 2003, 100, 2, 66-80.

67. Teopa Calva, E.; Picón Núñez, M.; Rodríguez Toral, M.A. Thermal integration of trigeneration systems. Applied Thermal Engineering 2005, 25, 973-984.

68. Ghosh, S.; De, S. Energy analysis of a cogeneration plant using coal gasification and solid oxide fuel cell. Energy 2006, 31, 345-363.

69. Yokoyama, R.; Ito, K. Optimal design of gas turbine cogeneration plants in consideration of discreteness of equipment capabilities. J. Eng. Gas Turbines Power 2006, 128, 336-343.

70. Rosen, M.A. Energy, environmental, health and cost benefits of cogeneration from fossil fuels and nuclear energy using the electrical utility facilities of a province. Energy for Sustainable Development 2009, 13, 42-50.

71. Kanoglu, M.; Dincer I.; Rosen, M.A. Exergetic performance analysis of various cogeneration systems for buildings. ASHRAE Transactions 2007, 113(Part 2), 105-112.

72. Misa, T.; Crisford, M.; Jain, S.; Bansal, P.K. Thermodynamic analysis of an in-situ cogeneration plant. Proceedings of the Institution of Mechanical Engineers, Part A: Journal of Power and Energy. 2007, 221, 591-602.

73. Gusdorf, J.; Douglas, M.A.; Szadkowski, F.; Yang, L.; Limouse, E.; Manning M.; Swinton, M. Residential total energy system installation at the Canadian Centre for Housing Technology. Cogeneration and Distributed Generation Journal 2008, 23, 1, 33-51.

74. Bertaa, G.L.; Pratob A.P.; Garbarino, L. Design criteria for distributed cogeneration plants. Energy 2006, 31, 1403-1416.

75. Funk, J.E. Thermochemical hydrogen production: past and present. Int. J. Hydrogen Energy 2001, $26,185-190$. 
76. Organisation for Economic Co-operation and Development. Nuclear Production of Hydrogen: Proc. Third Information Exchange Meeting; Oarai, Japan, OECD Publishing, 2006.

77. Schultz K.; Herring, S.; Lewis, M.; Summers, W. The hydrogen reaction. Nuclear Engineering International 2005, 50, 10-19.

78. Le Duigou, A.; Borgard, J.M.; Larousse, B.; Doizi, D.; Allen, R.; Ewan, B.C.; Priestman, G.H.; Elder, R.; Devonshire, R.; Ramos, V.; Cerri, G.; Salvini, C.; Giovannelli, A.; De Maria, G.; Corgnale, C.; Brutti, S.; Roeb, M.; Noglik, A.; Rietbrock, P.-M.; Mohr, S.; de Oliveira, L.; Monnerie, N.; Schmitz, M.; Sattler, C.; Orden Martinez, A.; de Lorenzo Manzano, D.; Cedillo Rojas, J.; Dechelotte S.; Baudouin, O. HYTHEC: An EC funded search for a long term massive hydrogen production route using solar and nuclear technologies. Int. J. Hydrogen Energy 2007, 32, 1516-1529.

79. Forsberg, C.W. Hydrogen, nuclear energy and advanced high-temperature reactor. Int. J. Hydrogen Energy 2003, 28, 1073-1081.

80. Suppiah, S.; Li, J.; Sadhankar, R.; Kutchcoskie, K.J.; Lewis, M. Study of the hybrid Cu-Cl cycle for nuclear hydrogen production. In Nuclear Production of Hydrogen: Proc. Third Information Exchange Meeting; Oarai, Japan. OECD Publishing, 2006; pp. 231-238.

81. Arif Khan, M.; Chen. Y. Preliminary process analysis and simulation of the Copper-Chlorine thermochemical cycle for hydrogen generation. In Nuclear Production of Hydrogen: Proc. Third Information Exchange Meeting; Oarai, Japan. OECD Publishing, 2006; pp. 239-248.

82. Lewis, M.A.; Serban, M.; Basco, J.K. Hydrogen production at $<550^{\circ} \mathrm{C}$ using a low temperature thermochemical cycle. Proc. ANS/ENS Exposition; New Orleans, 2003.

83. Steinfeld, A. Solar thermochemical production of hydrogen-A review. Solar Energy 2005, 78, 603-615.

84. Steinfeld, A. Solar hydrogen production via a two-step water-splitting thermochemical cycle based on $\mathrm{Zn} / \mathrm{ZnO}$ redox reactions. Int. J. Hydrogen Energy 2002, 27, 611-619.

85. Lubis, L.I.; Dincer, I.; Rosen, M.A. Preliminary life cycle assessment of nuclear-based hydrogen production using thermochemical water decomposition. In Proc. 3rd IASME/WSEAS Int. Conf. on Energy and Environment; Cambridge, UK, 23-25 Feb. 2008; pp. 487-494.

86. Utgikar, V.; Ward, B. Life cycle assessment of ISPRA Mark 9 thermochemical cycle for nuclear hydrogen production. J. Chemical Technology 2006, 81, 1753-1759.

(C) 2009 by the authors; licensee Molecular Diversity Preservation International, Basel, Switzerland. This article is an open-access article distributed under the terms and conditions of the Creative Commons Attribution license (http://creativecommons.org/licenses/by/3.0/). 